https://doi.org/10.48009/1_iis_2010_439-444

\title{
TECHNOLOGY: CONVENIENCE OR NECESSITY
}

Karen L. Paullet, Robert Morris University, paullet@ rmu.edu

Jamie L. Pinchot, Robert Morris University, jllst1 @ mail.rmu.edu

Daniel R. Rota, Robert Morris University, rota@ rmu.edu

\begin{abstract}
We live in an "always-on" world where people are expected to stay connected with friends, family members, and co-workers. We are becoming a culture that is dependent on technology to complete the activities in our daily lives. Technology is changing our culture in such a way that we may be expected to be available and "online" at anytime of the day or night. This exploratory study of 88 undergraduate and graduate students at a midAtlantic university found that students depend on technology to fulfill their communication and information seeking needs and to complete their daily activities. This study argues that students are becoming increasingly dependent on technology to accomplish their daily activities and thus forgetting how to complete these tasks without the use of technology.
\end{abstract}

Key words: technology dependency, communication, Internet usage, technology failure

\section{INTRODUCTION}

We live in an "always-on" world where people are expected to stay connected with friends, family members, and co-workers. We are becoming a culture that is dependent on technology to complete the activities in our daily lives. Our cell phones, computers, and other mobile devices provide conveniences in terms of communicating and seeking information. Technology is changing our culture in such a way that we may be expected to be available and "online" at anytime of the day or night. The technologies that started out to provide assistance in completing our daily tasks have now become a vital part of survival. The intent of this research is to examine and identify the extent to which university students have become dependent on technology. Could students easily accomplish their daily activities if technology failed? There is a threat that students have become so absorbed in technology that they are allowing it to control their lives.

\section{LITERATURE REVIEW}

Living in the $21^{\text {st }}$ century we are surrounded by technology to complete even our basic needs. In the past one would see a family dining in a restaurant where the parents would entertain their children with paper and crayons. In 2010, families keep their children entertained with hand held games, cell phones, and DVD players. We are constantly engaging in communication and entertainment via technology. Higgins [5] states "technology has drawn us into our interconnected webs, in the office, on the street, on the park bench, to the point that we exist virtually everywhere except in the physical world" Are we living in a society that has become too dependent on technology?

Meserve [10] has found that problems arise when individuals excessively rely on technology. He believes that there are two areas of concern in regard to technology dependency. The first is that people stop teaching and learning information, activities which were considered common knowledge before the advent of technology. For example, children send and receive dozens of emails and text messages on a daily basis to communicate with friends and family. But are they forgetting, or did they ever truly learn how to communicate verbally or in face-to-face situations? The second concern that Meserve [10] points out is that this reliance on technology has convinced people that they can have everything faster, better, bigger and have an economic advantage over others. A dial-up modem in the 1990's was the technology people used to access the Internet from their homes and work places. At the time, dial-up technology was remarkable. As we waited patiently; it would sometimes take 5 to 10 minutes for a browser to become available. As we keyed in our topics of interest we would wait 60 seconds or longer for a page to load. With the origination and implementation of broadband, DSL, and cable we are connected to the Internet within seconds. As we key in our topics we expect the page to appear instantly. If the page does not appear within a couple of seconds, instead of waiting patiently, we re-key the topic or web URL address again hoping for faster results. 
Generation $\mathrm{Y}$ students may prove to be more dependent on technology than earlier generations. Generation Y, known as Millennials (also the Digital Generation) [3], are people who were born between the years 1977 and 1994. Generation Y accounts for more than 25 percent of today's population. Junco and Mastrodicasa's [6] study of 7,705 U.S. college students reported that 97 percent of students own a computer and 94 percent own a cell phone. These statistics indicate that Generation Y, which accounts for the majority of students attending college in 2010, may have learned to communicate primarily through the use of technology.

A recent study conduct by Hemmer [4] used focus groups to determine the impact of text messaging on communication. The study sought to answer questions such as "Do you think text messaging displaces face-to-face communication?" and "Do you think text messaging is addicting?" The author sought to identify reasons for the use of text messaging and if text messaging displaced faced-to-face communication. The study was primarily examined through a technique called analysis of words. The analysis of words technique examines repetition and categories of key words. The focus group consisted of five males and five females. Each of the females and four males believed that text messaging could be used for multitasking purposes. Half of the group consisting of four females and one male believed that text messaging could be an addiction. The entire focus group found that text messaging is used to stay connected with family and friends. Both male and female focus groups divulged that they use text messaging to avoid face-to-face communication [4].

A person's dependency on technology goes beyond computers and cell phones. Members of a search and seizure rescue in 2008 were concerned that boaters are relying on global positioning systems (GPS) to navigate the waters. GPS technology will not be a problem as long as the mariners have a solid foundation of coastal navigation. If technologies were to fail, the boaters must know how to use a compass, divider, and paper charts or maps [11].

In October 2009, two Northwest Airlines pilots missed their airport by approximately 150 miles. Air traffic controllers tried to contact the pilots for over an hour and 18 minutes. Controllers requested help from other planes in the air to contact the Northwest pilots [9]. After an investigation from federal safety officials in March 2010, it was determined that the pilots lost track of time while using their laptops. The pilots failed to notice the messages sent by the dispatchers because they were engrossed in using their personal laptops [2]. Using laptops during flight is a violation of the airlines flight deck policies. Neither pilot ever had a prior accident or incident violation in their combined 31,000 hours of flight time.

A study conducted by Kakabadse, et.al. [7] asked 1,277 students in the United Kingdom between the ages of 11-18 to complete a survey to determine if they are addicted to technology. The researchers sought to collect data on student's use of technology mediated communication such as mobile phones, text messaging, computers and social network sites. A total of 267 surveys were returned with an almost equal representation of male and female students. In terms of technology usage, $95 \%$ of students had access to computers, mobile phones and the Internet. Students reported they used text or instant messaging most often when contacting friends. The majority of students indicated they sent and received approximately 20 texts per day. The study revealed that peer pressure is the main reason that they make themselves continually available by mobile phone. The majority of students, $32 \%$, reported that they spend between 1-2 hours on social network sites. Approximately $63 \%$ of students reported being addicted to the Internet and $53 \%$ believe they are addicted to mobile phones.

\section{PURPOSE OF STUDY}

In an "always on" world, people are expected to stay connected 24 hours a day. Prior studies have found that problems arise when individuals rely excessively on technology [10]. This reliance on technology can result in the loss of the communication of information and knowledge that we transmit to each other. This study argues that students are becoming increasingly dependent on technology to accomplish their daily activities and thus forgetting how to complete these tasks without the use of technology. This study explores the following research questions:

RQ1: Are university students depending on technology to fulfill their communication and information seeking needs?

RQ2: If technology failed, would university students know how to communicate and complete their daily activities?

\section{METHODOLOGY}


This study examined technology dependency of undergraduate and graduate students ages 18 or older at a mid-Atlantic university. The researchers designed the survey based on previous literature on technology dependency. A quantitative methodology was selected as a means to determine student's dependency on technology. A pilot test of the survey was distributed to a group of 20 students at the university in November 2009. After reviewing the responses, it was necessary to make changes to several of the questions. The survey was redrafted based on the student's responses.

The survey questions focused on obtaining information from students on technology dependency. The survey questionnaire was a fivepage, 39 question document which was comprised of four sections. The first section focused on participant demographics to include gender, age, and education. The second section addressed the students Internet and cell phone usage, to include text messaging and social network sites. The third section focused on the student's technology needs to complete their daily activities. Lastly, the fourth section sought information regarding the student's reliability on technology.

\section{Sample}

The sample consisted of 88 undergraduate and graduate students at a mid-Atlantic university. A 5\% margin of error with a $95 \%$ confidence level was used for this study. The study was a convenience sample surveying both undergraduate and graduate students. The researchers administered the survey to students from the School of Computer and Information Systems and Communications during their scheduled class time in January 2010. Students were informed that taking the survey was strictly voluntary and would not impact their current or future relations with the university. The survey supplied students with contact information for future reference if they were interested in the findings.

\section{RESULTS}

The objective of this study was to examine and identify the extent to which university students have become dependent on technology. Male and female genders were not represented in proportion in the participant sample. More than half of the research participants were male, 58, (68\%) with 30 females, $(34 \%)$. The questionnaire requested participants to indicate their age. Of the 88 students, 40 students

Volume XI, No. 1, 2010 were between the ages of 20-29, 29 were ages 30-39, 13 were ages $40-49$ and 7 were ages 50 and over.

All 88 students that completed the survey responded that they use the Internet. A majority of the participants, $88 \%$, indicated that they use the Internet more than once a day, while $12 \%$ indicated that they use the Internet once a day. The study revealed that there is not a correlation between frequency of Internet use and technology dependency. Survey questions addressed how the students receive the majority of their phone calls. Approximately $75 \%$ of participants receive the majority of their phone calls by cell phone. The majority of students, 93\%, use text messaging as a form of communication. Of the students that text, 53\% prefer sending and receiving text messaging to talking on the phone. In the recent study conducted by Hemmer [4] which determined the impact of text messaging on communication, the researcher found that participants believed that text messaging is used to avoid face-to-face communication. The students that use text messaging, 49\%, report sending and receiving less than 10 messages per day with $8 \%$ indicating that they send and receive over 75 messages on a daily basis.

The survey asked participants if they were a member of any social networking site. Ninety-one percent of the students use social networking sites. Of the students that use social networking sites, $83 \%$ use Facebook, 19\% use MySpace and 48\% use LinkedIn. Students can belong to more than one social networking community.

Research Question 1 sought to determine if students depend on technology to fulfill their communication and information seeking needs. A series of questions were asked in order to address this question. In order to determine a person's dependency to fulfill information seeking needs the researchers asked participants if they talk on their cell phone while driving. Over $91 \%$ of respondents reported talking on their cell phones while driving, with $50 \%$ of students indicating that they text while driving. Additionally, $64 \%$ of students talk in public places on their cell phones. A total of 57 students, $65 \%$, responded that they would return home to retrieve their cell phones if they left them behind by accident.

In order to determine the need to communicate and stay connected in an "always-on" world; students were asked if they ever took a work related phone call while they were on vacation. A total of 64 students, $73 \%$, answered yes and 24 students, $27 \%$, answered no. There is a statistically significant 
relationship between age and taking a work related phone call while on vacation indicating the need to communicate via technology at any time (chi-square $=16.847, d f=2, \mathrm{p}<.001)$. The observed significance level is .000 which is greater than the customary .05 indicating that the results did not happen by chance. As a student's age progresses, the likelihood of them taking a work related phone call while on vacation increases. Approximately $82 \%$ of students between the ages of 30 and 39 have taken work related calls while on vacation. Additionally, $100 \%$ of students over the age of 40 have taken work calls on vacation.

Research Question 2 sought to determine whether students would know how to communicate and complete their daily activities if technology failed. Students were asked if they could spend an entire day without using a computer, cell phone, or mobile device assuming that it was not a workday. The survey revealed that 53 students, $60 \%$, could not spend and entire day without the use of technology devices while 35 students, $40 \%$, could spend an entire day without using a computer, cell phone, or mobile device. In order to answer the research question, students were asked if it would bother them if technology failed and they could not be reached. A total of 47 students, $54 \%$, answered yes and 41 students, $46 \%$, answered no. There is a statistically significant relationship between gender and technology failure (chi-square $=16.380, d f=1, \mathrm{p}<$ .000 ). Approximately $62 \%$ of males would not be bothered if technology failed and they could not be reached.

Students were asked if they would know how to research information using a card catalog in the library if technology failed. Approximately 64 students, $73 \%$, could find information in a library using a card catalog while 24 students, $27 \%$, would have no idea how to manually find information in a library. Ninety-nine percent of students responded that the Internet is the first place they go to find information. Not a single student listed the library as their primary way to find information, while $1 \%$ of students turn to television for their information needs. Students were also asked if all of the phone numbers stored in their cell phones were deleted, would they know the numbers of the people they call frequently. The study revealed that 66 students which are $75 \%$ of the sample would not know the phone numbers of the people they call most frequently while 22 students, $25 \%$, would know the numbers. An additional question addressed the use of GPS for directions. Over $80 \%$ of students rely solely on GPS for directions without having a backup such as a map, atlas, or printed document.

\section{DISCUSSION}

The Internet and telecommunications technologies have become easily accessible and are used for almost every facet of daily living throughout the world. The results of this study support MacLean [8] that we have become a culture of people that are almost completely dependent on technology. The first research question sought to determine if students depend on technology to fulfill their communication and information seeking needs. The study revealed that there was not a direct correlation between technology usage and the student's ability to communicate. However, the study did reveal that $73 \%$ of students feel the need to stay connected while on vacation by taking work related phone calls. The majority of students between the ages of 30 and 39 have taken work related calls. All students over the age of 40 have taken work related calls while on vacation as shown in figure 1 .

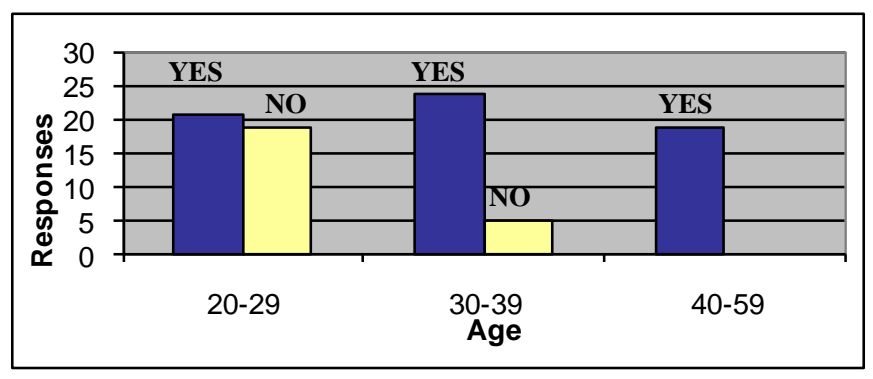

Figure 1 - Students age in regard to taking work related calls on vacation.

With the growth of communications technologies and the Internet, there is always a continual presence that makes people want to stay in touch with friends, family and even co-workers. The Internet, cell phone, and other technologies have freed us from geographic constraints that permit us to stay connected to anyone in the world. Today, cell phones and other mobile devices are not simply used for telephone communications and text messaging. Many mobile devices can also access the Internet and a variety of applications, making them equivalent to a pocketsized computer with wireless Internet access.

The second research question examined if students would know how to communicate and complete their daily activities if technology failed. According to Meserve [10], reliance on technology results in the 
loss of previously accumulated knowledge because we cease to pass on knowledge that has become obsolete. As we look around the malls, walk down the streets and sit in restaurants and airports one will see dozens of people accessing computers, using cell phones, sending text messages and accessing mobile devices. As we wait at a traffic light and look at the car in front of us we will see GPS devices, cell phones and DVD players being used. Our society is constantly engaging in technology related activities. We are living in a society that uses technology to pass the time. Approximately $60 \%$ of students revealed that they could not spend an entire day without using technology devices. Additionally, 54\% of students would be bothered if technology failed. Males were less likely to be bothered by technology failure than women. The study showed a statistical significance between technology failure and gender as seen in figure 2 .

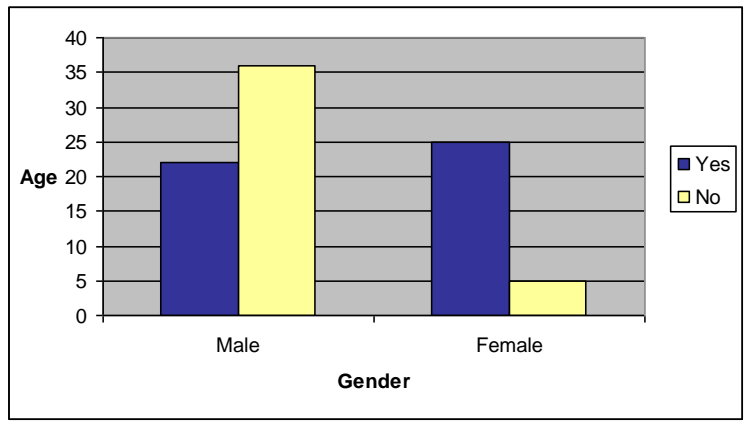

Figure 2 - Technology Failure and Gender

Although not the intent of the original study, additional findings were discovered as a result of the statistical analysis. The study revealed that $13 \%$ of students would feel panicked or upset if they were not able to access their social networking sites. Over $80 \%$ of respondents use the Internet to look up phone numbers while $14 \%$ revealed that they use a phone book. Students were asked if they thought it was rude for someone to take a phone call while meeting or speaking with others in person. Only $33 \%$ of students thought that it was rude if someone interrupted a conversation to take a phone call. The study showed a significant relationship between age and answering a cell phone while meeting with friends. We are now living in a world where disruptive communication is becoming acceptable.

\section{LIMITATIONS AND FUTURE RESEARCH}

Volume XI, No. 1, 2010
The research reported in this study was limited to the School of Computer and Information Systems and Communications. Future studies should include students from different schools within the university. The demographic characteristics revealed that male participants outnumbered female participants. This could have been attributed to conducting the survey using students from the School of Computer and Information Systems and Communications in which the majority of the students are male. Additional research should focus on the amount of time a person engages in technology related activities. The use of the Internet, cell phones, text messaging, accessing social network sites and using mobile devices should be considered in determining technology dependency.

\section{CONCLUSION}

Studies are needed to improve our understanding of technology dependency. Using technology is inevitable as it surrounds us in almost every facet of our everyday lives. There is no doubt that the Internet and other telecommunication technologies have added conveniences to our lives that make it simpler to function. We can now look up information at the touch of a button on a mobile phone, anytime and anywhere. We have GPS systems to guide us through unfamiliar territory. We can stay in touch and contact others from our cell phones, social networks, and laptop computers at any time of the day or night. However, despite these conveniences, one must not forget how to survive if all technology failed.

Realizing that technology continues to progress, we should be concerned that there are some situations in which the original skill set must be maintained. For instance, hospitals all over the world depend on technology to assist with procedures and to keep track of data and medical information of patients. Imagine if one morning all of the computers in a hospital crashed. One would hope that the doctors, nurses and staff could continue patient care without hesitation or pause by reverting back to methods and procedures used before technology.

As we look to the future we can only wonder if our children will be able to research information without the Internet? Will they be able to navigate the highways using a paper map? Will our greatgrandchildren know how to write a note by hand or will they depend solely upon typing to communicate (via text messaging, email, or a new technology)? 
These manual skills may be lost as time goes on and technology displaces traditional ways of doing things. It should not require a massive outage or power failure for us to see the extent to which we have become dependent on technology. Instead we should proactively ensure that we continue to pass on the knowledge of traditional information seeking and communication skills. We should take advantage of the conveniences offered by technology, but not allow technology to become a necessity.

\section{REFERENCES}

1. Agre, P, E. (2001, January). Welcome to the always-on world. IEEE Spectrum, 10-13. University of California.

2. Ahlers, M, M. (2010, March 18). NTSB:

Wayward Northwest pilots awake but distracted. Cnn.com. Retrieved on April 2, 2010 fromhttp:www.cnn.com/2010/us/03/18/waywar d.pilots.ntsb/index.html

3. CRM Trends (2010). Evolving consumer demographics. Retrieved on January 23, 2010 fromwww.crmtrends.com/consumerdemographi cs.htm

4. Hemmer, H. (2009). Impact of text messaging on communication. Journal of Undergraduate Research at the Minnesota State University.

5. Higgins, A. (24 January, 2010). Have we become posthuman digital zombies? Pittsburgh PostGazette.Section, B, p. 1.

6. Junco, R., \& Mastrodicasa, J. (2007) Connecting to the net generation. NASPA

7. Kakabadse, A., Kakabadse, N., Bakey, S., \& Myers, A. (2009, September). Techno addicts, your person addicted to tehnology. Sigel Press, Medina, Ohio.

8. MacLean, D. (2003, October 7). Dependency on technology. Digital Trends. Retrieved on October 6,2010 from http://news.digitaltrends.com/talkback/27/dependency-on-technology-printerfriendly

9. Mayerowitz, S. ( 22 October 2009). Northwest airlines pilots miss airports by 150 miles.
ABC News. Retrieved on April 1, 2010 from http://abcnews.go.com/print?id=8892976

10. Meserve, L.A. (1998). The problem with relying on technology. Ohio Journal of Science, 98(3): 34-38, 1998.

11. Sorum, A. (2003, November 3). Over reliance on GPS risks safety: dependence on technology seen as An increasing safe boating threat. Retrieved on February 22, 2010 from http://boatsafetymaintneance.suite.101.com/articl e.cfm/over_reliance_on_gps_risks_safety 